\title{
Photochemical and thermal degradation of a naturally occurring dye used in artistic painting. A chromatographic, spectrophotometric and fluorimetric study on saffron
}

\author{
Vida Vickackaite, ${ }^{1}$ Aldo Romani, ${ }^{2}$ Danilo Pannacci, ${ }^{2}$ and Gianna Favaro ${ }^{2, \dagger}$ \\ ${ }^{1}$ Department of Analytical and Environmental Chemistry, Vilnius University, 2006 Vilnius, Lithuania \\ ${ }^{2}$ Dipartimento di Chimica - Università di Perugia - 06123 Perugia, Italy
}

\begin{abstract}
Saffron is a yellow substance which is extracted from the stigmas of Crocus sativus L. and is used in painting, cooking and medicine. In this paper six components (trans and cis crocins) with carotenoid structures were separated from natural saffron by HPLC and were characterised by their absorption and emission spectra. Photochemical and thermal processes which degrade the dye were also investigated. The effect of light promoted the cis $\rightleftarrows$ trans isomerization, while the thermal effect detached the glycosyl moieties.
\end{abstract}

\section{INTRODUCTION}

In order to establish conservation procedures and preservation conditions for art works, the constituent materials must be identified [1, 2]. Several naturally occurring organic dyes have been known and used in painting for centuries. Among them, saffron was the most frequently used yellow dye in manuscripts [3] and in textile dyeing [4]. Saffron is also used as a food additive for flavouring and colouring, and is also known for its therapeutic properties [5-8].

Saffron is obtained by drying the stigmas from the flower of Crocus sativus L., whose cultivation probably began during prehistoric Greek times. About 200 stigmas are required to obtain $1 \mathrm{~g}$ of colorant [9].

The basic components of saffron, which are responsible for its strong yellow-red colour, are cis- and trans-crocins, a family of water-soluble carotenoids $[8,10]$. Crocins are glucosyl esters of a polyene dicarboxylic acid (8,8'-diapocarotene-8,8'-diolic acid), named crocetin, whose central unit consists of seven conjugated double bonds and four chain methyl groups. One or both of the end-groups are esterified with glucose or gentiobiose; in the di-esters, they can be equal or different [10]. Their relative amounts markedly depend on the source from where saffron has been extracted [11]. Saffron also contains picrocrocin and safranal in smaller quantities. Picrocrocin is a colourless glycoside of the aglycone, 2,6,6trimethyl-4-hydroxy-1-carboxaldehyde-1-cyclohexene, and is mainly responsible for the bitter taste of saffron, while the aroma of the saffron essential oil is due to safranal [8]. It is a monoterpene aldehyde, formed by the hydrolysis of the picrocrocin during

${ }^{\dagger}$ E-mail: favaro@unipg.it drying and storage of saffron [12]. The structures of the saffron components are presented in Figure 1.

Several analytical techniques have been used to identify saffron and its components: UV-visible spectroscopy [7, 13, 14], Fourier-transform infrared and Raman spectroscopy [9, 13], HPLC [6, 8, 11, 14-16], HPLCMS [10], GC [6, 15], GC-MS [5, 12], and NMR [13, 17].

Some of these techniques are destructive, and require sampling which affects the integrity of the artwork under study. Recently, UV-visible fluorimetric techniques have been proposed for investigating materials used in art $[18,19]$. These techniques are reliable, very sensitive and specific. Moreover, fluorimetry can be applied in situ and therefore is a non-destructive technique, which avoids sampling and therefore does not damage the object under examination [20]. To the best of our knowledge, there are no data in the literature about fluorimetric investigations on saffron.

The aim of this work was to investigate the composition and spectral properties of natural saffron and study the photochemical and thermal processes which are responsible for its degradation. Spectrophotometric, fluorimetric and chromatographic techniques were used. Solutions, as well as painted papers, were investigated. In order to gain more insights into the degradation mechanism of saffron, particular attention was focused on the behaviour of the individual saffron components.

\section{MATERIALS AND METHODS}

2.1. Materials. Saffron was purchased from Zecchi (Florence, Italy); crocetin from Sigma. Arabic gum was from Winsor \& Newton, London. Methanol and acetonitrile were from Merck. To prepare samples of painted 


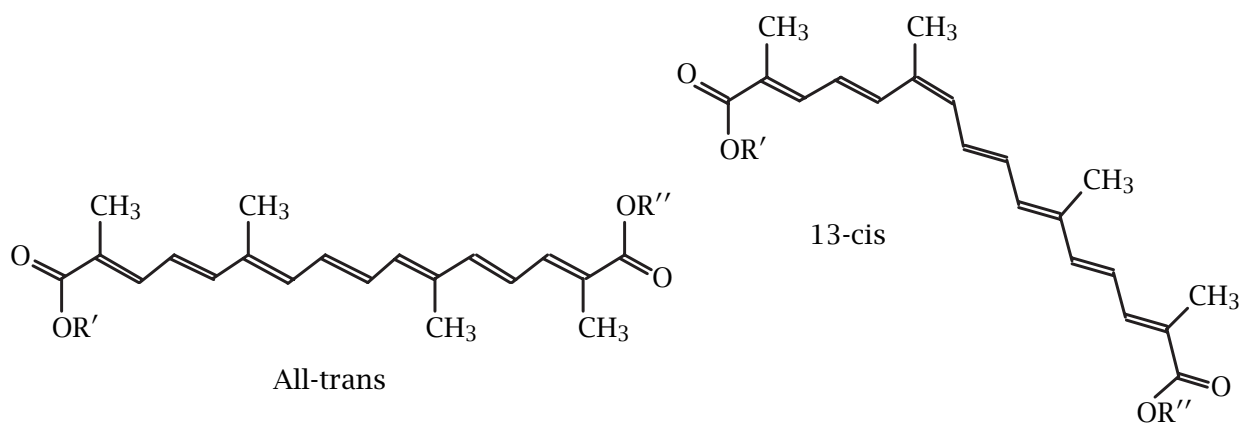

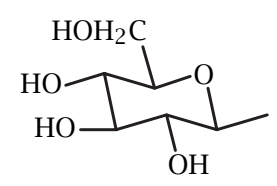

X

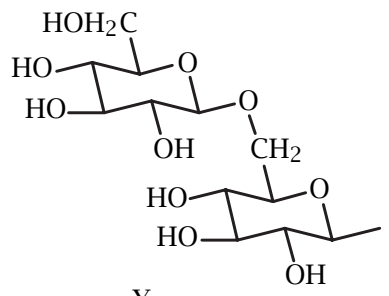

Y

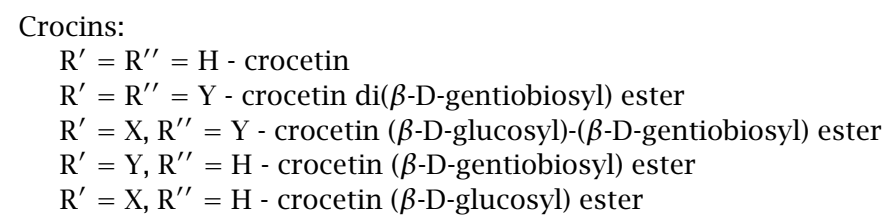

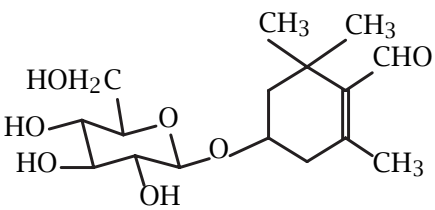

Picrocrocin<smiles>CC1=C(C)C(C)(C)CC=C1</smiles>

Safranal

Figure 1. Structures of saffron components.

surfaces, saffron was mixed with arabic gum as a binder and painted onto a piece of paper.

2.2. Equipment. Absorption spectra in solution were recorded using a Perkin Elmer Lambda 16 spectrophotometer. Emission spectra were obtained using a Spex Fluorolog-2 1680/1 spectrofluorimeter, controlled by the Spex DM 3000F spectroscopy software.

For the accelerated photo-ageing trials carried out in methanol solution, a mercury lamp $(500 \mathrm{~W})$, filtered through a $436 \mathrm{~nm}$ interference filter, was used. For accelerated photo-ageing of painted layers a $150 \mathrm{~W}$ Xenon lamp, filtered through a Pyrex filter, was used.

A HPLC system equipped with Waters 600 pump and controller, 2487 dual $\lambda$ absorbance and photodiode array detector was used. For analytical purposes,
XTerra $\mathrm{RP}_{18}$ columns (Waters, $10 \mathrm{~cm}$ length, $4.6 \mathrm{~mm}$ internal diameter, $5 \mu \mathrm{m}$ particle size) and a XTerra $\mathrm{RP}_{18}$ guard column (Waters, $2 \mathrm{~cm}$ length, $3.9 \mathrm{~mm}$ internal diameter, $5 \mu \mathrm{m}$ particle size) were used. For preparative purposes, a HPLC system equipped with Waters 600 pump, 600E system controller, Lambda-Max model 481 LC spectrophotometer and XTerra Prep $\mathrm{RP}_{18}$ column (Waters, $30 \mathrm{~cm}$ length, $19 \mathrm{~mm}$ internal diameter, $10 \mu \mathrm{m}$ particle size) was used.

2.3. Measurement conditions. For analytical HPLC determinations, acetonitrile-water mixtures, with and without $1 \%$ acetic acid, were used. The gradient program was the following: initially, 0-1 min, acetonitrile-water $(15: 85 \mathrm{v} / \mathrm{v}) ; 24 \mathrm{~min}$, linear change to acetonitrile-water $(80: 20 \mathrm{v} / \mathrm{v})$ and this was maintained 
Table 1. HPLC data and assignments of the six saffron components monitored at $450 \mathrm{~nm}$.

\begin{tabular}{cccl}
\hline Peak & $\begin{array}{c}\text { Retention time } \\
\text { min }\end{array}$ & $\begin{array}{c}\text { Peak area } \\
\%\end{array}$ & \multicolumn{1}{c}{ Assignments } \\
\hline 1 & 8.45 & 8.5 & trans crocetin $(\beta$-D-gentiobiosyl) ester \\
2 & 9.96 & 58.0 & trans crocetin di $(\beta$-D-gentiobiosyl) ester \\
3 & 10.58 & 24.5 & trans crocetin $(\beta$-D-glucosyl)- $(\beta$-D-gentiobiosyl) ester \\
4 & 11.31 & 2.0 & trans crocetin $($ di ? $)(\beta$-D-glucosyl) ester \\
5 & 11.72 & 4.5 & cis crocetin di $(\beta$-D-gentiobiosyl) ester \\
6 & 12.34 & 2.5 & cis crocetin $(\beta$-D-glucosyl)- $(\beta$-D-gentiobiosyl) ester \\
\hline
\end{tabular}

Table 2. Absorption, emission maxima ( $\mathrm{nm})$ and Stokes shifts $\left(\Delta v / \mathrm{cm}^{-1}\right)$ of saffron, crocetin and saffron coloured components in methanol solution.

\begin{tabular}{|c|c|c|c|c|c|c|c|}
\hline \multirow{3}{*}{$\begin{array}{c}\text { Compound } \\
\text { Saffron }\end{array}$} & \multicolumn{7}{|c|}{$\lambda_{\max }(\mathrm{nm})$} \\
\hline & \multicolumn{4}{|c|}{ Absorption } & \multicolumn{2}{|c|}{ Emission } & \multirow{2}{*}{$\frac{\Delta v / \mathrm{cm}^{-1}}{6450}$} \\
\hline & 256 & 319 & 431 & 456 & 646 & 686 & \\
\hline 1 & 254 & & 424 & 448 & $638(\mathrm{sh})$ & 685 & 6650 \\
\hline 2 & 257 & & 431 & $456(464)^{\mathrm{a}}$ & $648(\mathrm{sh})$ & 686 & 6500 \\
\hline 3 & 258 & & 431 & $455(464)^{\mathrm{a}}$ & $649(\mathrm{sh})$ & 687 & 6570 \\
\hline 4 & & & 429 & 452 & 647 & 687 & 6670 \\
\hline 5 & 260 & 316 & 426 & 450 & $644(\mathrm{sh})$ & 687 & 6690 \\
\hline 6 & 260 & 319 & 426 & $450(457)^{\mathrm{a}}$ & 644 & 688 & 6690 \\
\hline Crocetin & 249 & & 420 & 446 & $641(\mathrm{sh})$ & 685 & 6820 \\
\hline
\end{tabular}

a values in parentheses are in acetonitrile/water $(40 / 60, \mathrm{v} / \mathrm{v})$.

for $6 \mathrm{~min}$; $30 \mathrm{~min}$, back to the initial conditions. The flow-rate was kept constant at $1.0 \mathrm{ml} / \mathrm{min}$. Samples of $20 \mu$ l were injected.

For preparative purposes, methanol-water mixtures were used as eluent at ambient temperature. The gradient program was the following: initially, 0-1 min, methanol-water $(20: 80 \mathrm{v} / \mathrm{v}) ; 25 \mathrm{~min}$, linear change to methanol-water $(80: 20 \mathrm{v} / \mathrm{v})$, maintained for $5 \mathrm{~min}$; $30 \mathrm{~min}$, back to the initial conditions. The flow-rate was kept constant at $16 \mathrm{ml} / \mathrm{min}$. Samples of $400 \mu \mathrm{l}$ were injected.

The detection wavelength was $450 \mathrm{~nm}$. Fractions corresponding to six peaks were collected. The results obtained are summarized in Table 1 . The relative amounts of the different compounds decreased in the order: $2,3,1,5,6$, and 4 .

After separation, the solutions were evaporated using a rotor dryer at room temperature. For studies in solution, the powdery compounds were dissolved in methanol.

For fluorimetric measurements, sample concentrations were adjusted in order to keep the absorbance $\left(\lambda_{\text {exc }}=430 \mathrm{~nm}\right)$ at about 0.1 to avoid self-absorption of the fluorescence emission.

\section{RESULTS}

3.1. Absorption and fluorescence spectra of saffron and its components. Spectral features of natural saffron in methanol solution are shown in

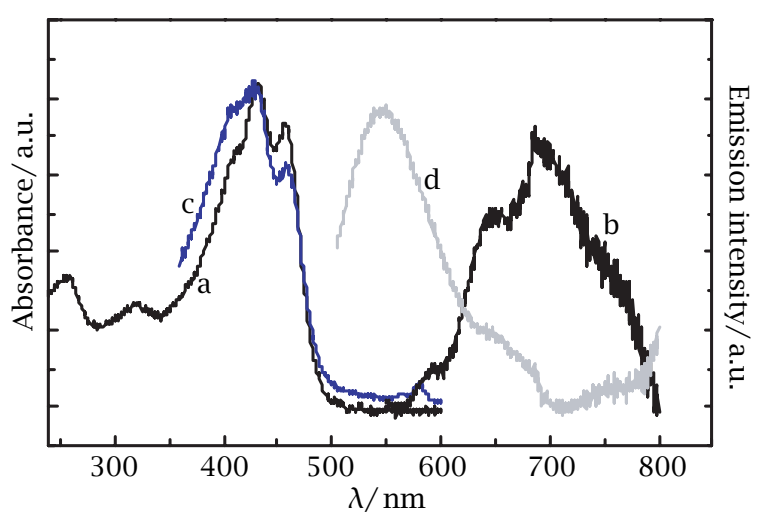

Figure 2. Absorption (a), fluorescence (b) and fluorescence excitation (c, in blue) spectra of natural saffron. The emission from a painted paper (d) is also shown.

Figure 2. After separation and drying, the absorption, fluorescence and fluorescence excitation spectra of each of the saffron components were recorded in methanol. Wavelength maxima are reported in Table 2 and compared with those of natural saffron and crocetin. Some measurements carried out in acetonitrile/water $(40 / 60, \mathrm{v} / \mathrm{v})$ showed that the colour bands were shifted to the red in the more polar solvent, as expected for $\pi, \pi^{*}$ transitions.

The absorption spectra obtained are characteristic of carotenoids. They exhibit a double-peaked band between 400 and $500 \mathrm{~nm}$ in the visible region and bands in 
the UV region, around $260 \mathrm{~nm}$, attributed to the glycosidic bond of crocins [7]. An absorption peak, between 320 and $340 \mathrm{~nm}$, referred to as the cis peak [21], was observed for 5 and 6 and was also present in the natural saffron. By comparison with literature data, compounds 1-4 were identified as trans-crocins, and 5 and 6 as ciscrocins. Information about structure was also obtained using an acidic eluent for HPLC separation, which did not affect the retention times of peaks 2, 3, 5, and 6 , but significantly increased the retention time of peak 1. This suggests that 1 is an undissociated acid which has a longer retention time in non-polar RP HPLC. These considerations along with the comparison of the sequence and relative amounts of the components obtained by elution with those reported in the literature $[8,10,11,14]$ and separated by similar RP columns, allowed all of the components to be identified (Table 1). The assignment is less certain for 4 , since it was present in such a low amount.

The fluorescence emissions are rather broad and quite similar to each other $\left(\lambda_{\max }=685-688 \mathrm{~nm}\right)$ and to that of saffron. The Stokes shifts, calculated using the longest wavelength peak of absorption and the shortest wavelength shoulder/peak of fluorescence, are very large and similar (ca. $6600 \mathrm{~cm}^{-1}$ ) for all the compounds investigated (Table 2). The fluorescence excitation spectra reproduce well the absorption ones; only small variations in the relative intensities of the two peaks of the colour band are observed. No appreciable oxygen quenching of the emission was found.

To investigate the behaviour of saffron on painted surfaces, samples were prepared by painting the saffron dye and arabic gum binder onto pieces of paper (water-painting technique). Similar samples but containing only the binder (in the absence of saffron), were also examined for the purpose of comparison. The fluorescence band of saffron (Figure 2, spectrum d) from a freshly prepared painted paper was found at $546 \mathrm{~nm}$. Its position was significantly shifted to a higher energy with respect to that in solution $(686 \mathrm{~nm})$.

3.2. Photochemical and thermal ageing. Due to natural ageing and exposure to solar irradiation, deterioration of saffron-painted surfaces (or coloured tissues), associated with changes in the original colour, may occur. In order to evaluate saffron deterioration, solutions and painted layers were exposed to natural and artificial ageing and subsequently analysed.

The absorption and fluorescence spectra of a freshly prepared saffron solution, a solution stored in the dark at room temperature for 75 days, and a solution irradiated ( $436 \mathrm{~nm}, \mathrm{Hg}$ line) for 2 hours were quite similar and few changes were detectable. However, HPLC analysis of this solution showed that irradiation had promoted a slight decrease in the intensity of the chromatographic peaks for 1,2 , and 3 and an increase in peaks 5 and 6 . Irradiation therefore appears to have shifted the equilibrium between the cis and transcrocins towards the cis isomers. These changes were almost undetectable in the absorption and fluorescence spectra because the spectra of all the components are very similar.

In order to discriminate the contribution made by the various saffron components to the degradation, the behaviours of the individual compounds were investigated upon irradiation and storage in the dark.

Photochemical reactions. Trans $\rightleftarrows$ cis photoisomerization is a typical reaction of molecular systems which bear several alternant CC bonds, like crocins [21, 22]. After separating the six components by preparative HPLC and drying, they were each dissolved in methanol. The solutions were irradiated for 100 minutes $\left(\lambda_{\mathrm{exc}}=\right.$ $436 \mathrm{~nm}$ ) and then spectrophotometrically and chromatographically analysed. The absorption bands in the visible region of the trans crocins (1-4) showed a very slight decrease in intensity with irradiation. A new, very weak band at $322 \mathrm{~nm}$, characteristic of cis crocins, was observed only in some cases. For the cis crocins (5 and 6 ), a marked decrease of the absorption band at about $320 \mathrm{~nm}$ was observed, indicating the occurrence of cis to trans photoconversion. Formation of trans isomers was also supported by a slight shift of the visible absorption bands to the red. As can be seen from the data in Table 2, trans isomers absorb in the visible at slightly higher wavelengths than cis isomers. An intensity increase, observed in the visible region, is also in line with this explanation, since the cis forms are less intensely coloured than the trans ones. For example, the molar absorption coefficients for the trans and cis crocetin di( $\beta$-D-gentiobiosyl) esters in aqueous solution are $89000 \mathrm{dm}^{3} \mathrm{~mol}^{-1} \mathrm{~cm}^{-1}\left(\lambda_{\max }=443 \mathrm{~nm}\right)$ and $63350 \mathrm{dm}^{3} \mathrm{~mol}^{-1} \mathrm{~cm}^{-1}\left(\lambda_{\max }=437 \mathrm{~nm}\right)$, respectively [17].

The HPLC chromatograms gave better evidence of the occurrence of photo-isomerisation. Formation of cis-crocins was observed, to a limited extent, in the irradiated 1, 2, and 3 trans components, while the ciscrocins photoisomerised much more efficiently to the trans forms. Examples of chromatograms and absorption spectra after irradiation for a trans (3) and a cis (6) compound are shown in Figures 3 and 4. Noting the retention times and spectral maxima, it can be observed that the two isomeric forms involved are the same and, under irradiation, tend to a photostationary state where the trans isomer dominates. A similar relationship was observed for the trans (2) and cis (5) couple.

The fluorescence spectra of the irradiated solutions were quite similar to those of the non-irradiated solutions, showing only a slight increase in emission intensity for the irradiated cis solutions. This was probably due to the contribution made by the photoproduced, more fluorescent, trans isomers.

Dark reactions. Three series of experiments were carried out in the dark to investigate the thermal 

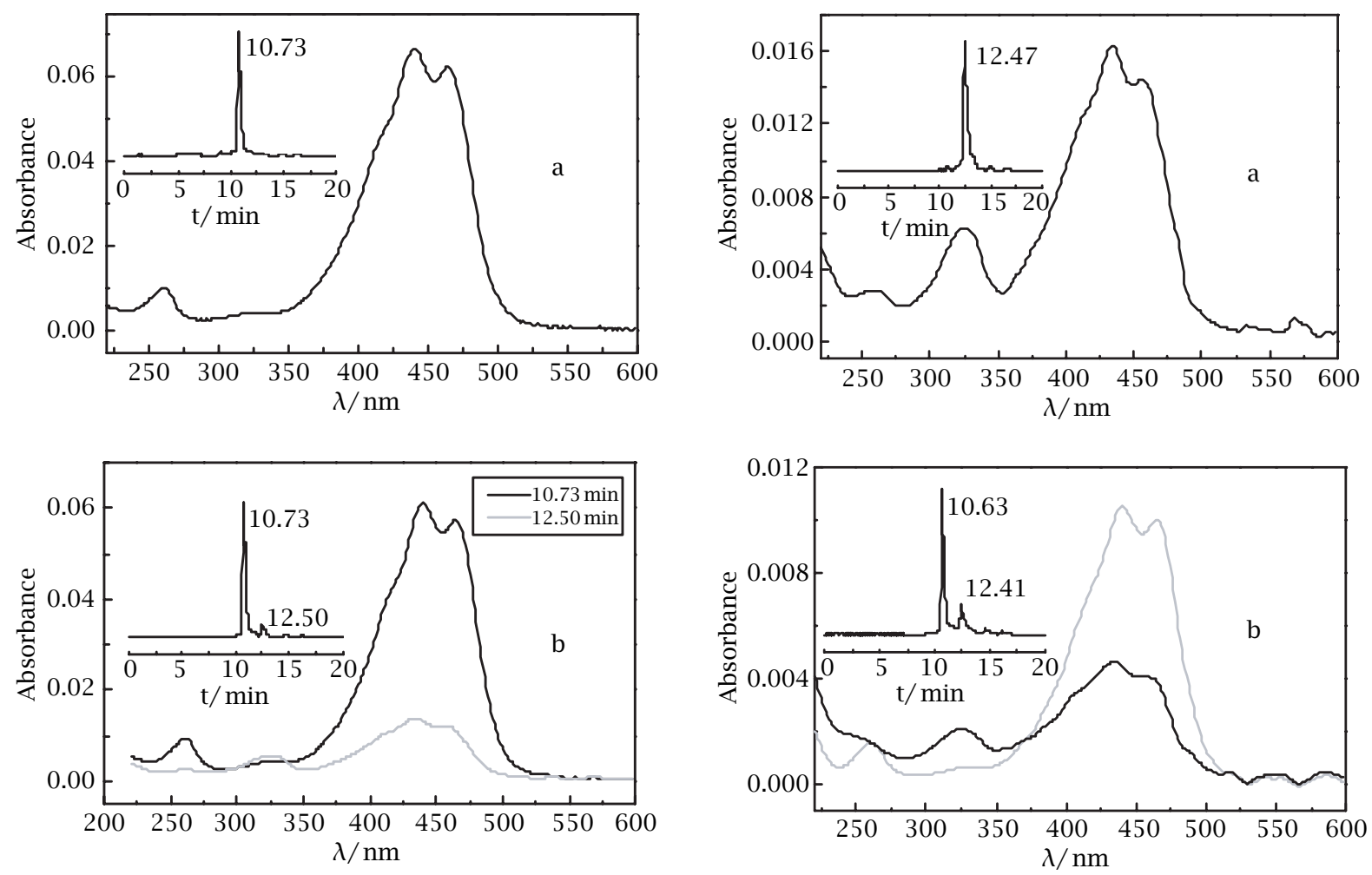

Figure 3. Absorption spectra and HPLC chromatograms (inserts) of the methanol solution of 3: a) immediately after preparative HPLC; b) irradiated for $100 \mathrm{~min}$.

stability of the saffron components:

(i) storage in the dark at room temperature for 75 days in the solid powdery phase (all six compounds),

(ii) keeping the solutions in the dark at $40{ }^{\circ} \mathrm{C}$ for four hours (compounds 2 and 5),

(iii) keeping both the solution and the powder in the dark at $-25^{\circ} \mathrm{C}$ for 20 days (compound 2).

(i) The powdery solid compounds were stored in the dark at room temperature $\left(18 \pm 2{ }^{\circ} \mathrm{C}\right)$ for 75 days and then analysed by spectrophotometry and HPLC chromatography. The changes observed in the absorption spectra of the six compounds after storage were more marked than those found after irradiation. The bands in the visible region of the trans compounds $-1,2$, and 3 -shifted to shorter wavelengths, as shown in Figure 5 for 2 .

Considering the cis compounds, the spectrum of 6 did not appreciably change in the visible region, but the absorbance significantly increased in the UV region. In contrast, the absorption spectrum of 5 was completely different from the initial one, indicating that this compound underwent a net chemical transformation

Figure 4. Absorption spectra and HPLC chromatograms (inserts) of the solution of 6: a) immediately after preparative $H P L C, b)$ irradiated for $100 \mathrm{~min}$.

(Figure 5). There were also more marked changes in the fluorescence spectra of the cis compound (Figure 6) than in those of the trans compounds; the original fluorescence decreased, while new broad emissions appeared at $\lambda<650 \mathrm{~nm}$.

The results from the HPLC analyses of the solutions of the aged dyes showed that all the compounds underwent significant changes after storage in the dark. New products were formed, most of which had similar absorption spectra but longer retention times than the starting compounds. Several new peaks were obtained from compounds 1, 2 (Figure 7) and 3, while 4, 5 (Figure 8) and 6 were almost completely transformed yielding mostly one product.

(ii) The effect of temperatures higher than room temperature was investigated on the principal trans (2) and cis (5) components of natural saffron. Their absorption spectra were recorded before and after keeping the solutions at $40{ }^{\circ} \mathrm{C}$ for 4 hours. The results were similar to those obtained with samples kept at room temperature for a longer time (see section i).

(iii) The main trans component (2) was also investigated at a temperature lower than the normal ambient temperature. It was stored at $-25^{\circ} \mathrm{C}$, in the dark for 20 days, as both powder and methanol solution, and then analysed at room temperature. The 

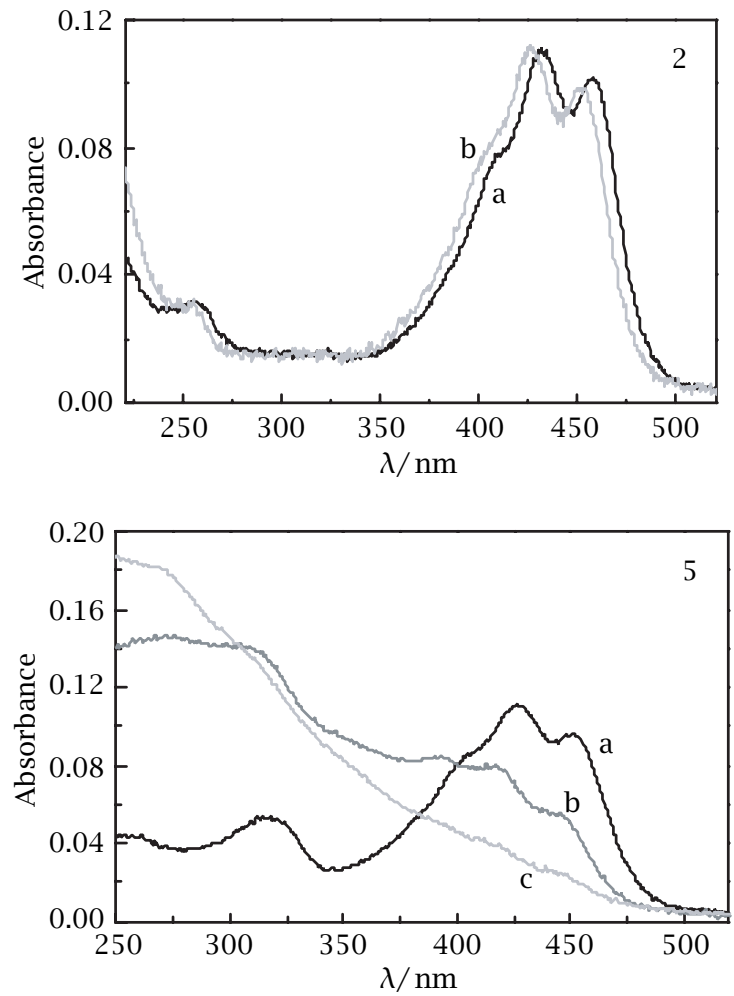

Figure 5. Absorption spectra in methanol of the solutions of 2 and 5 immediately after preparative HPLC (a), after storage as powder in the dark at room temperature for 30 days (b) and for 75 days (c).

HPLC chromatograms and the absorption spectra for the fresh solution, the solution stored at $-25^{\circ} \mathrm{C}$, the solution of the powder stored at $-25^{\circ} \mathrm{C}$, the solution stored at room temperature and the solution of the powder stored at room temperature are compared in Figure 9. It can be observed that there was significantly less degradation in the samples stored at low temperature, as expected, but, surprisingly, this was also true for samples stored in solution than for samples stored in solid state at the same temperature for the same time. In fact, no product was observed from the solution stored at $-25^{\circ} \mathrm{C}$, while one product was detected for the powder stored under the same conditions. Two additional species were observed at room temperature. These products have longer retention times than the starting compound and absorb at slightly shorter wavelengths, but they do not exhibit the characteristic band of the cis isomers at about $320 \mathrm{~nm}$.

Ageing of painted surfaces. The painted papers were naturally aged, keeping them at ambient temperature, in the dark and exposed to sunlight over a period of 26 months. To accelerate photochemical ageing, they were also irradiated with a Xenon lamp for four hours.

Fluorescence spectra of painted papers that were freshly prepared (spectrum a), kept in the dark (spec-
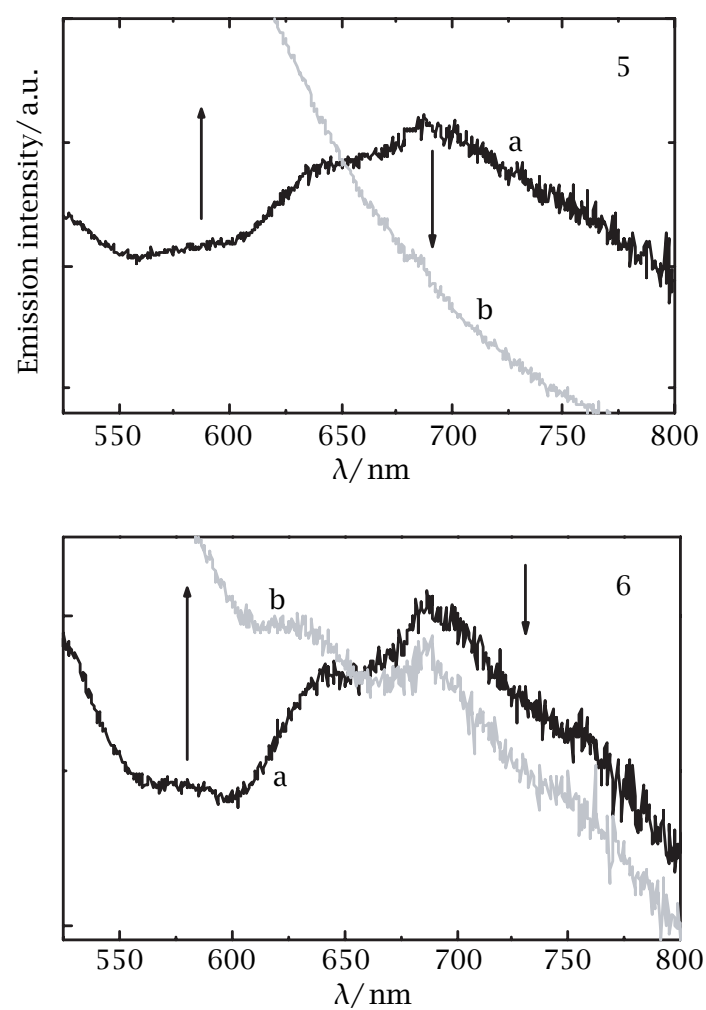

Figure 6. Fluorescence spectra $\left(\lambda_{\mathrm{exc}}=430 \mathrm{~nm}\right)$ of 5 and 6 immediately after preparative HPLC (a) and after storage of dried crocins in the dark at room temperature for 75 days (b).

trum b) and exposed to sunlight (spectrum c) are compared in Figure 10. The band at $439 \mathrm{~nm}$ is due to the paper emission since it was observed for the uncoloured paper, either in the presence or absence of the binder; the band at $546 \mathrm{~nm}$ belongs to the colourant. It can be observed that the degradation was much more significant when the sample was exposed to both sunlight and daily temperature excursions rather than to only the effect of temperature. After 26 months, the fluorescence band of saffron had practically disappeared and only a weak, blue-shifted shoulder (ca. $510 \mathrm{~nm}$ ) could be detected (Figure 10, spectrum c).

Given the limited duration of artificial irradiation, the changes produced by the accelerated photo-ageing were less marked, but were in the same direction as natural ageing.

\section{DISCUSSION}

The chromatographic separation and spectral characterization of the six saffron components has already been described in the literature [6, 10, 11, 14-16], while fluorescence spectra have never been reported. Other carotenoids have been reported to exhibit dual emissive properties, derived from $S_{1}$ and $S_{2}$, which contribute 

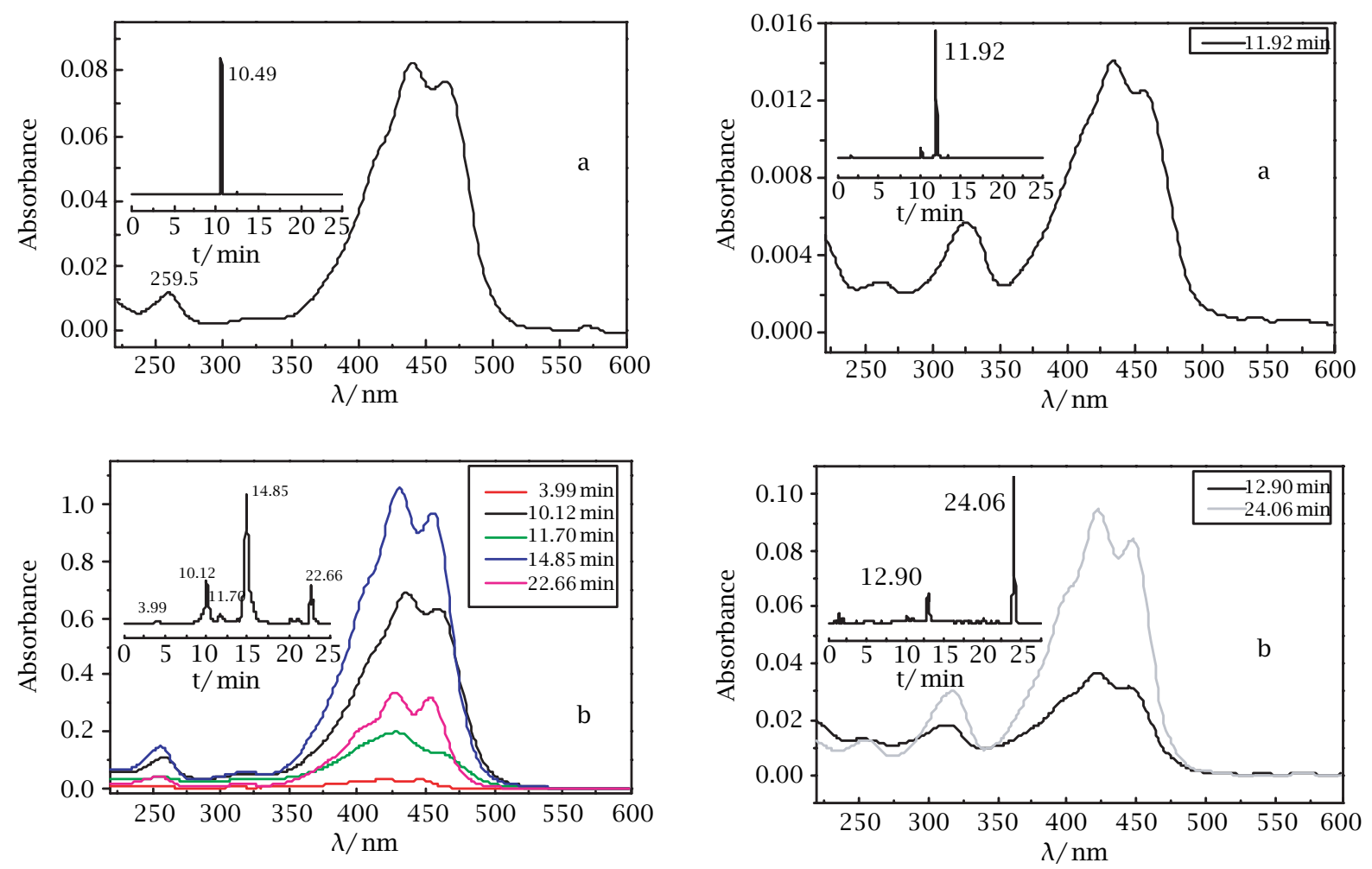

Figure 7. HPLC chromatograms and corresponding absorption spectra of 2: a) after preparative HPLC, b) stored dried in the dark at room temperature for 75 days.

differently to the overall emission, depending on the structure [23]. For the carotenoids in natural saffron, we believe that the observed emissions occur from a relaxed geometry of the $S_{1}$ state, which could be a common configuration for each trans-cis couple. The similarity of the emission features of different molecules, suggests that all of them undergo the same excited state rearrangement, attaining a similar molecular conformation in the emitting, thermally equilibrated, excited state.

The different, blue-shifted emission of saffron on painted surfaces can be reasonably explained by assuming that the rigidity of the medium does not allow molecular rearrangement to occur. Thus the emission comes from the Franck-Condon unrelaxed state, directly reached by light absorption.

The effect of irradiation on saffron and saffron components is clearly related to the occurrence of trans $\rightleftarrows$ cis photoisomerization. From spectrophotometric and chromatographic analyses of the irradiated solutions, it is clear that, upon irradiation, the two isomers tend towards a photostationary state where the cis isomer makes up a much lower percentage (see Figures 4 and 5) than the trans isomer. The relative amount of isomers approximately corresponds to that found in natural saffron (Table 1) where it was due to exposure to sunlight.

Figure 8. HPLC chromatograms and corresponding absorption spectra of 5: a) immediately after preparative HPLC, $b$ ) stored dried in the dark at room temperature for 75 days.

The similar features of the chromatographic results obtained from saffron in different laboratories, also using different samples, indicate that saffron is reasonably stable in the crystalline state. The reactivity of the saffron components stored in the dark, with consequent degradation (Figures 6-9), observed even at room temperature, was unexpected, as was their greater reactivity in the solid state compared with that in solution (Figure 10). The nature of the thermal products was different from that of the photoproducts. No sign of trans $\rightleftarrows$ cis isomerisation was detected in the dark reactions, since lower activation energy processes are favoured. Longer retention times and slight blue shifts of the absorption bands (but little change in the band shape) of the products denote the formation of less polar species which maintain the alternating double-single bond structure. This behaviour is attributed to the detachment of the glucose moieties. This hypothesis was supported by calculating the dipole moments using semi-empirical methods (PM3) on optimised geometry. The results show that the dipole moment decreased from the di-ester (trans crocetin $\operatorname{di}(\beta$ D-gentiobiosyl)), $\mu=3.092$ Debye, to the monoester (trans crocetin ( $\beta$-D-gentiobiosyl)), $\mu=1.845$ Debye, and trans crocetin, $\mu=1.925$ Debye. 

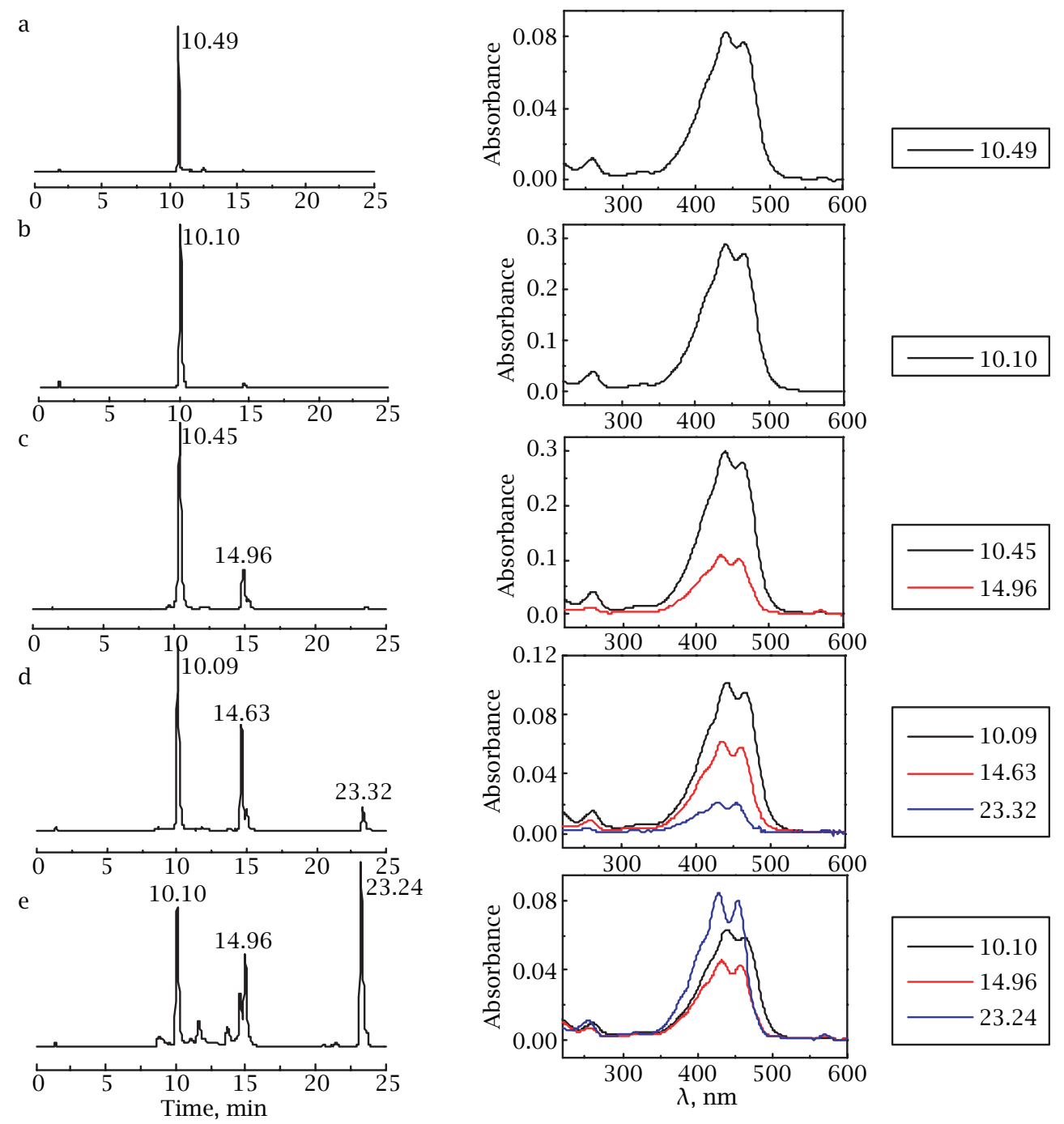

Figure 9. HPLC chromatograms and absorption spectra of solutions of 2: immediately after preparative HPLC separation (a), stored in the dark for 20 days at $-25^{\circ} \mathrm{C}$ in solution (b) and in powder (c), kept at room temperature (ca. $\left.18{ }^{\circ} \mathrm{C}\right)$ in solution (d) and powder (e).

What cannot be easily explained is why the individual components degrade in solid phase but not (or to a lesser extent) in natural saffron. According to the literature [22, 24], humidity is an important factor in the degradation of carotenoids. The degradation rate of saffron carotenoids increased with increased water activity [22]. In the present case, residual water can remain encapsulated in the stored powder. When the solid is dissolved in methanol, the water is diluted in a larger volume. This could explain why degradation was faster in the dry state than in solution. The reason why the composition of solid saffron does not appreciably change when stored in the dark, while its separated components do, could be due to the extraction procedures which do not involve water. Another reason could be that each component, and particularly the cis iso- mers that undergo the most drastic changes and make up a very low percentage, are in a diluted environment.

\section{CONCLUSIONS}

This study has confirmed that high performance liquid chromatography is the best technique for separating the components of saffron and investigating their photochemical and thermal reactions. Absorption and fluorescence spectroscopies can be used to identify saffron but are of little help in recognising the components once they have been separated by chromatography, because of the similar spectral features of all the compounds.

The results on degradation indicate that these compounds have different photochemical and thermal 


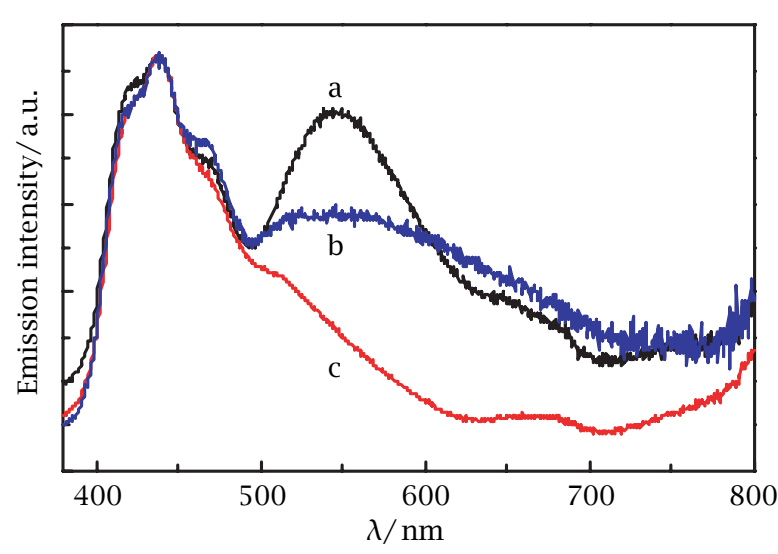

Figure 10. Fluorescence spectra $\left(\lambda_{\mathrm{exc}}=254 \mathrm{~nm}\right)$ of saffron painted surfaces: freshly prepared (a, black), stored for 26 months in the dark at room temperature (b, blue), and under ambient conditions (c, red).

reactivities, the latter being favoured by both temperature and humidity. The extent of degradation is strongly influenced by the nature of the medium and is particularly favoured by a closely packed molecular arrangement. For these reasons the degradation of the water-painted paper was very significant.

The differences found in both the emission pattern and degradation rate of a saffron-painted paper compared with saffron solution have, once again, demonstrated that the results from studies in solution of colourants used in painting cannot be used to extrapolate their behaviours on painted surfaces. However, they can provide information about the behaviour in the solid state which can be used to determine the best conditions for storage.

\section{ACKNOWLEDGMENTS}

The research was funded by the Ministero per l'Università e la Ricerca Scientifica e Tecnologica (Rome) and the University of Perugia in the framework of the Programmi di Ricerca di Interesse Nazionale (project: "Photoprocesses of interest for applications"). One of us (V.V.) is grateful to the Italian Consiglio Nazionale delle Ricerche for a fellowship NATO CNR OUTREACH.

\section{REFERENCES}

[1] L. Burgio, D. A. Ciomartan, and R. J. H. Clark, J. Molecular Structure 405 (1997), 1.

[2] L. Burgio and R. J. H. Clark, Spectrochimica Acta Part A 57 (2001), 1491.

[3] R. J. H. Clark, J. Mol. Struct. 347 (1995), 417.
[4] M. Liakopoulou-Kyriakides, E. Tsatsaroni, P. Laderos, and K. Georgiadou, Dyes and Pigments 36 (1998), 215.

[5] A. V. Zareena, P. S. Variyar, A. S. Gholap, and D. R. Bongirwar, J. Agric. Food Chem. 49 (2001), 687.

[6] J. Escribano, G.-L. Alonso, M. Coca-Prados, and J.-A. Fernandez, Cancer Letters 100 (1996), 23.

[7] O. Orfanou and M. Tsimidou, Food Chem. 57 (1996), 463.

[8] P. Lozano, M. R. Castellar, M. J. Simancas, and J. L. Iborra, J. Chromatogr. A 830 (1999), 477.

[9] P. A. Tarantilis, A. Beljebbar, M. Manfait, and M. Polissiou, Spectrochim. Acta Part A 54 (1998), 651.

[10] P. A. Tarantilis, G. Tsoupras, and M. Polissiou, J. Chromatogr. A 699 (1995), 107.

[11] N. Li, G. Lin, Y.-W. Kwan, and Z.-D. Min, J. Chromatogr. A 849 (1999), 349.

[12] P. A. Tarantilis and M. G. Polissiou, J. Agric. Food Chem. 45 (1997), 459.

[13] M. K. Assimadis, P. A. Tarantilis, and M. G. Polissiou, Appl. Spectrosc. 52 (1998), 519.

[14] M.-R. Van Calsteren, M. C. Bissonnette, F. Cormier, C. Dufresne, T. Ichi, J. C. Yves LeBlanc, D. Perreault, and I. Roewer, J. Agric. Food Chem. 45 (1997), 1055.

[15] P. Lozano, D. Delgado, D. Gómez, M. Rubio, and J. L. Iborra, J. Biochem. Biophys. Methods 43 (2000), 367.

[16] A. V. Loskutov, C. W. Beninger, G. L. Hosfield, and K. C. Sink, Food Chemistry 69 (2000), 87.

[17] G. Speranza, G. Dadà, P. Manitto, D. Monti, and P. Gramatica, Gazz. Chim. Ital. 114 (1984), 189.

[18] E. Renè de la Rie, Stud. Conserv. 27 (1982), 1; 27 (1982), 65.

[19] C. Miliani, A. Romani, and G. Favaro, Spectrochim. Acta Part A 54 (1998), 581; C. Miliani, A. Romani, and G. Favaro, J. Phys. Org. Chem. 13 (2000), 141; G. Favaro, C. Miliani, A. Romani, and M. Vagnini, J. Chem. Soc. Perkin Trans. 2 (2002), 192.

[20] C. Clementi, C. Miliani, A. Romani, and G. Favaro, in Ravenna '03, Proceedings Conferenza Nazionale Prove non Distruttive Monitoraggio Diagnostica 2003, p. 110.

[21] L. Zechmeister, Cis-trans isomeric carotenoids, vitamins A and arylpolyenes, Springer Verlag, Wien, 1962.

[22] M. Tsimidou and C. G. Biliaderis, J. Agric. Food Chem. 45 (1997), 2890.

[23] Y. Yamano, M. Mimuro, and M. Ito, Chem. Soc. Perkin Trans. 1 (1997), 2713.

[24] K. Selim, M. Tsimidou, and C. G. Biliaderis, Food Chemistry 71 (2000), 199. 


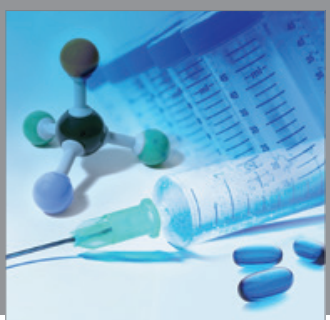

International Journal of

Medicinal Chemistry

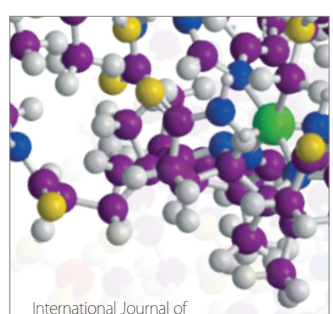

Carbohydrate Chemistry

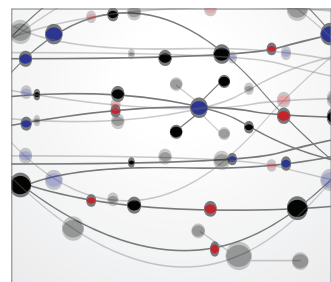

The Scientific World Journal
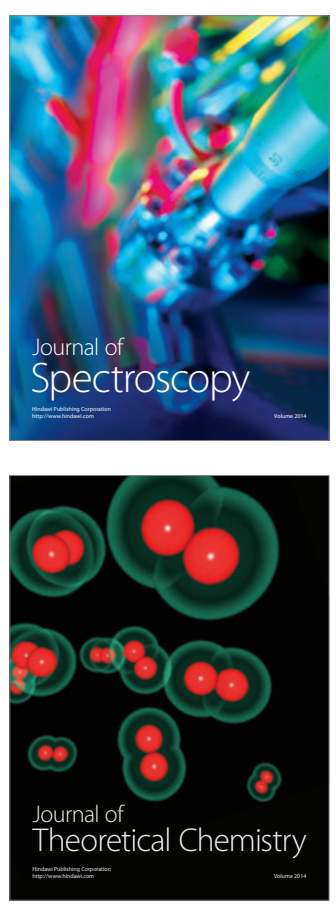
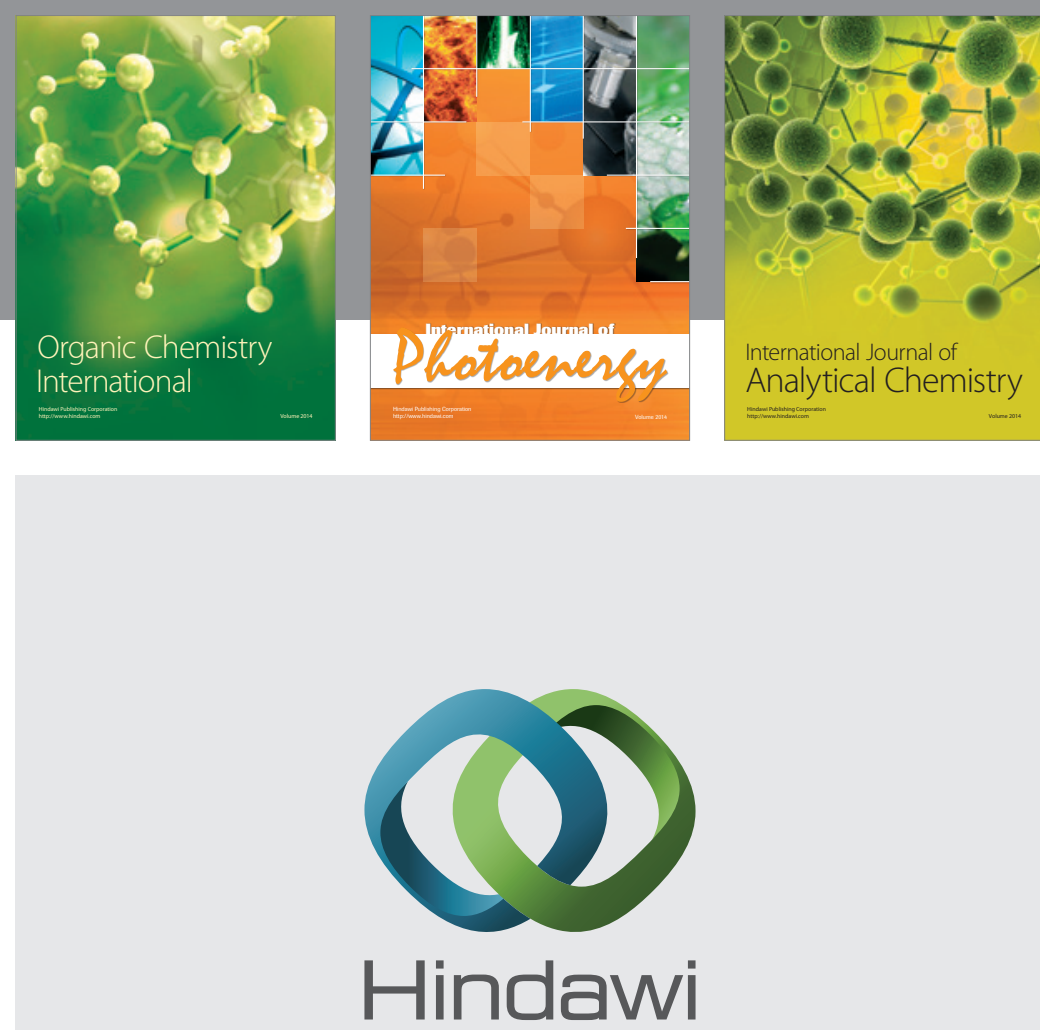

Submit your manuscripts at

http://www.hindawi.com
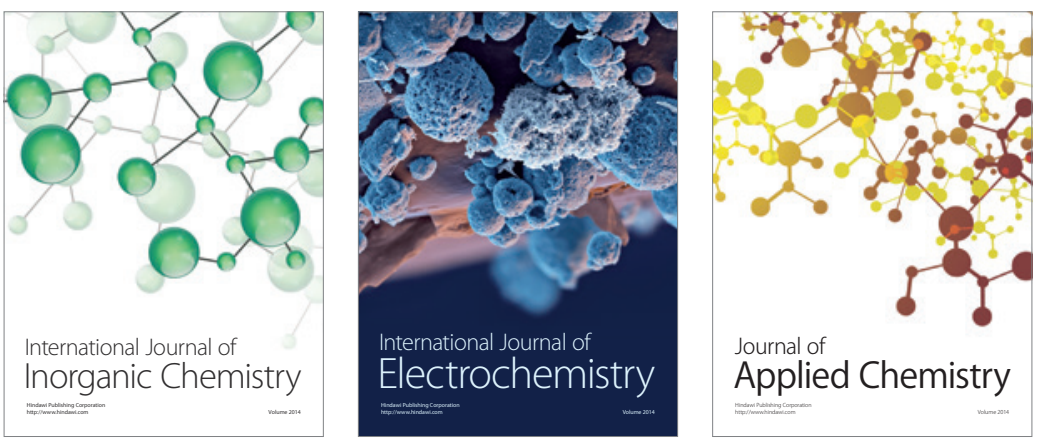

Journal of

Applied Chemistry
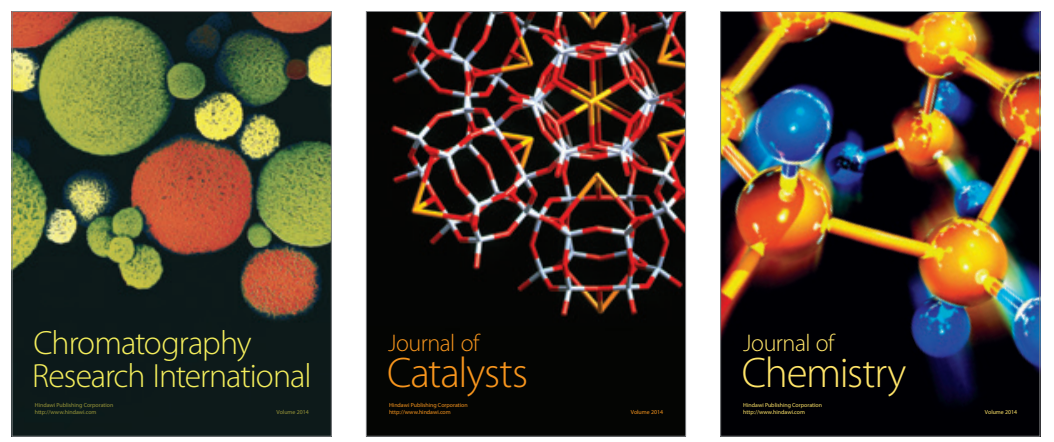
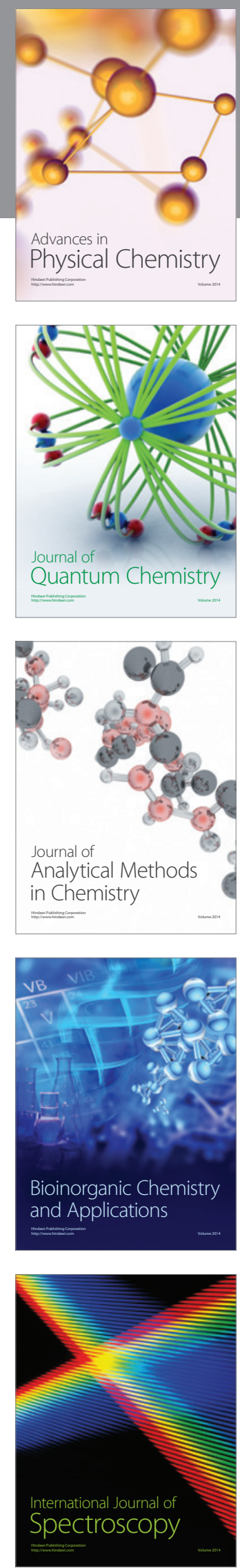